\title{
Assessment of the Thermal Performance of Timber Walls under Nominal or Moisture and Temperature Dependent Properties
}

\author{
Maja Danovska $^{1}$, Giovanni Pernigotto ${ }^{1}$, Paolo Baggio ${ }^{2}$, Andrea Gasparella ${ }^{1}$ \\ ${ }^{1}$ Free University of Bozen-Bolzano, Bolzano, Italy \\ ${ }^{2}$ University of Trento, Trento, Italy
}

\begin{abstract}
Materials thermal properties are generally assumed equal to nominal values in building simulation codes, even if they depend on both temperature and moisture content. For some materials, such as timber, this hypothesis can bring inaccuracies affecting the predicted building energy performance. In this research, a MATLAB $® 1 D$ heat and mass transfer model was developed according to the finite difference approach, with material thermal conductivity function of water vapour partial pressure and temperature. After calibration against laboratory experiments on spruce $X L A M$ specimens, annual simulations were run for 110 Italian climates and specific hourly heat fluxes compared to those determined with nominal properties.
\end{abstract}

\section{Introduction}

Building simulation codes such as EnergyPlus and TRNSYS can be adopted to calculate the building energy consumption. Some of these codes implement also simplified heat and mass transfer $H M T$ models, which can be used to predict the hygrothermal performance of envelope opaque components by knowing materials' properties and their dependence on temperature and humidity (Straube and Burnett, 1999). Simple and complex HMT models can be distinguished: the former ones typically adopt constant thermal properties while the latter ones consider also the effect of material temperature and moisture content. A popular simple model is the Glaser method, a steady-state method based on decoupled vapour diffusion and Fourier heat transfer. An example of software implementing a complex HMT model is WUFI, a transient thermal and hygric simulation code adopting moisture retention functions, sorption isotherm and suction curves.

Even if assuming constant properties is an acceptable hypothesis for most building materials, timber thermal conductivity is strongly affected by moisture content and temperature. Porous materials such as wood, indeed, are characterised by a discontinuous solid matrix and voids with both liquid water and a mixture of gaseous phases (air and water vapour). In a simple dry material, heat transfer is a superimposition of heat conduction through solid and gas, radiation inside the pores and convection associated to air flow. When a material is moistened, besides the latent heat flux, there is an additional contribution to heat conduction through the non-moving liquid film. All these complex heat exchanges can be modelled through the apparent thermal conductivity (Baggio et al., 2001; Bomberg and Shirtliffe, 1978), which depends on material density, porosity, average temperature, moisture content and flux direction (Troppová et al., 2015).

The different heat transfer mechanisms are combined also with moisture transfer, which is due to liquid flow, capillary suction, air movement and vapour diffusion. Indeed, there is a direct relationship between heat and mass transfer in porous materials since an enthalpy transfer occurs alongside with mass motion (Chaker and Sotehi, 2014), which can depend also on temperature gradient (Luikov, 1975). Consequently, a moisture redistribution phenomenon occurs often inside porous materials after the application of a thermal gradient (Rudtsch, 2000), affecting both heat transfer and representativeness of the apparent thermal conductivity.

Despite this, tabulated thermal conductivity-values given by manufacturers are generally evaluated in laboratories under standard conditions of temperature and humidity. However, as explained above, operative conditions may result in a deviation with respect of the nominal value of thermal conductivity and subsequently in a different energy performance of the whole building (Budaiwi and Abdou, 2013). For instance, considering the incidence of temperature on thermal conductivity, large deviations from nominal values were observed by Abdou and Budaiwi (2004) for general insulators and by Suleiman et al. (1999) for timber. Similarly, changes of moisture content can alter the thermal conductivity as seen by Jerman and Černý (2012) for some general insulators and by Budaiwi and Abdou (2013) for fibrous insulators, and by Karamanos et al. (2008) for stone wool.

Because of the aspects discussed above, a characterisation of thermal conductivity as a function of temperature and moisture content can improve the accuracy of building performance simulation. In this framework, this research investigated to what extent the variability of the thermal conductivity influences the heat transfer through a spruce $X L A M$ wall in the Italian climates. The impact of temperature and humidity on thermal conductivity was first investigated experimentally and then a 1D HMT model was developed. Annual simulations were run for 110 climates and specific hourly heat fluxes compared to those calculated with nominal thermal conductivity. 


\section{Methods}

\section{Experimental investigation}

The first activities performed in this research were addressed to develop a correlation between thermal conductivity and material's temperature and water vapour partial pressure. As specified in the introduction, the focus was on timber materials and, in particular, spruce was considered. 4 spruce specimens of about $0.2 \mathrm{~m} \mathrm{x} 0.2 \mathrm{~m} \mathrm{x}$ $0.05 \mathrm{~m}$ (Figure 1) were selected and their thermal conductivity characterised at different temperatures and humidity contents.

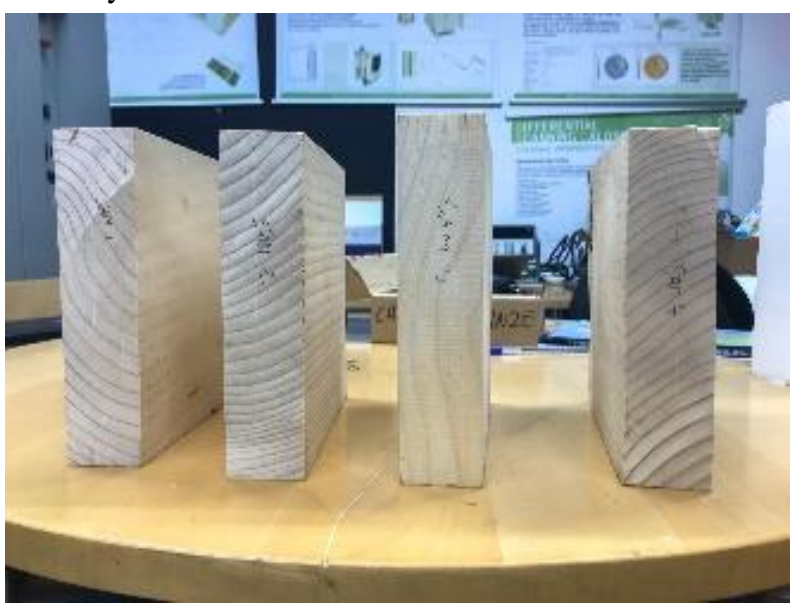

Figure 1: The four analysed wooden specimens.

Measurements were performed with a Netzsch HFM 436/3 Lambda $^{\mathrm{TM}}$ in compliance with ISO 8301 and EN 12664 and EN 12667. During measurements, the specimens' temperatures were varied between $10{ }^{\circ} \mathrm{C}$ and $50{ }^{\circ} \mathrm{C}$. An ATT Angelantoni DM340 climatic chamber was used for the conditioning process and reference conditions were set according to EN ISO 10456 (CEN, 2007). Besides the "as-is" conditions, with specimens in equilibrium with the laboratory environment (i.e., air temperature between $20{ }^{\circ} \mathrm{C}$ and $26{ }^{\circ} \mathrm{C}$ and relative humidity between 30 and $40 \%$ ), two conditioning setpoints were applied:

1. Humidified condition, at $23{ }^{\circ} \mathrm{C}$ and $80 \% R H$.

2. Dehumidified condition, at $23{ }^{\circ} \mathrm{C}$ and $10 \% R H$.

All specimens were exposed to the two aforementioned conditioning setpoints in the climatic chamber until reaching steady state condition. Weight variation was checked every $24 \mathrm{~h}$ with an electronic scale with a precision of $0.1 \mathrm{~g}$. Steady state was considered achieved when the weight variation was found less than $0.1 \%$. After that, each specimen was placed in the HFM and thermal conductivity measured.

\section{Numerical modelling approach}

To evaluate to what extent temperature and moisture affect the specific heat flux through a wall, a 1D heat and mass transfer dynamic model was developed, considering as heat transfer mechanisms, internal conduction and surface convection according to Fourier and Newton laws, respectively. The mass transfer was based on the study by Ferroukhi et al. (2017), considering only Fickian diffusion and the water vapor partial pressure as driving potential. The linear storage moisture capacity $C_{m}$ used in the mass transfer model was obtained from the experiments conducted on spruce specimens by Fitzpatrick et al. (2013). The governing equations for both heat and mass transfer adopted in the model are reported in Equation 1 and 2, respectively, and they were implemented in MATLAB $®$ environment.

$$
\begin{aligned}
& \rho c \frac{\partial T}{\partial t}-\nabla \cdot(\lambda \nabla T)=0 \\
& C_{m} \rho \frac{\partial p_{v}}{\partial t}-\nabla \cdot\left(\delta_{p} \nabla p_{v}\right)=0
\end{aligned}
$$

\section{Simulations}

A reference spruce $X L A M$ wall, with thickness of $30 \mathrm{~cm}$ and a $U$-value of $0.336 \mathrm{~W} \mathrm{~m}^{-2} \mathrm{~K}^{-1}$, and the properties summarised in Table 1, was modelled with a spatial discretisation of $2.5 \mathrm{~cm}$ (13 nodes) and $1 \mathrm{~h}$ timestep $m$. A single vertical wall was simulated, without the rest of the building, with constant internal boundary conditions (a temperature of $20^{\circ} \mathrm{C}$ and a relative humidity of $50 \%$ ) and variable external conditions (hourly air temperature and humidity profiles taken from CTI typical reference years, https://try.cti2000.it/). Surface convective heat transfer coefficients for horizontal heat flux, i.e., $20 \mathrm{~W} \mathrm{~m}^{-2} \mathrm{~K}^{-1}$ for the external side and $2.5 \mathrm{~W} \mathrm{~m}^{-2} \mathrm{~K}^{-1}$ for the internal one, were adopted. Considering that this was a preliminary development of the numerical model, the effects of incident solar irradiance and precipitations were neglected. Annual simulations were run for 110 different Italian climates with two different assumptions regarding the thermal conductivity:

1. nominal thermal conductivity $\lambda_{\text {nom }}$, which considers the thermal conductivity at $23{ }^{\circ} \mathrm{C}$, obtained from the experimental activity with specimens in equilibrium with the laboratory environment before conditioning (Table 1).

2. variable thermal conductivity $\lambda\left(T, p_{v}\right)$, which considers a thermal conductivity as a linear function of temperature and water vapour partial pressure at each node of the finite difference scheme of the model (Equation 3). Partial tests with thermal conductivity function of either material temperature $\lambda(T)$ or moisture content $\lambda\left(p_{v}\right)$ were performed as well.

Figure 2 shows steps for the coupling of the heat and mass transfer models. Through all the year, for each node $i$ and hourly timestep $m$ :

1. The temperatures of the internal and external air are imposed as boundary conditions, and the heat flux solved considering $\lambda_{\text {nom }}$ to obtain the temperature profiles through the wall.

2. Water vapor partial pressures at the wall surfaces are imposed as boundary conditions, and the diffusive problem across the wall solved to obtain the partial pressure profile through the wall.

3. Using partial pressure profile and temperature profiles of each time, the variable thermal conductivity $\lambda\left(T, p_{v}\right)$ (or either $\lambda(T)$ or $\lambda\left(p_{v}\right)$ for partial tests) is computed at each node and time according to Equation 3. 
4. By considering the same initial and boundary conditions, the conductive problem with $\lambda\left(T, p_{v}\right)$ (or either $\lambda(T)$ or $\lambda\left(p_{v}\right)$ for partial tests) is solved.

As initial conditions, the steady state temperature and partial pressure profiles through the wall found with the boundary conditions of the first timestep are assumed.

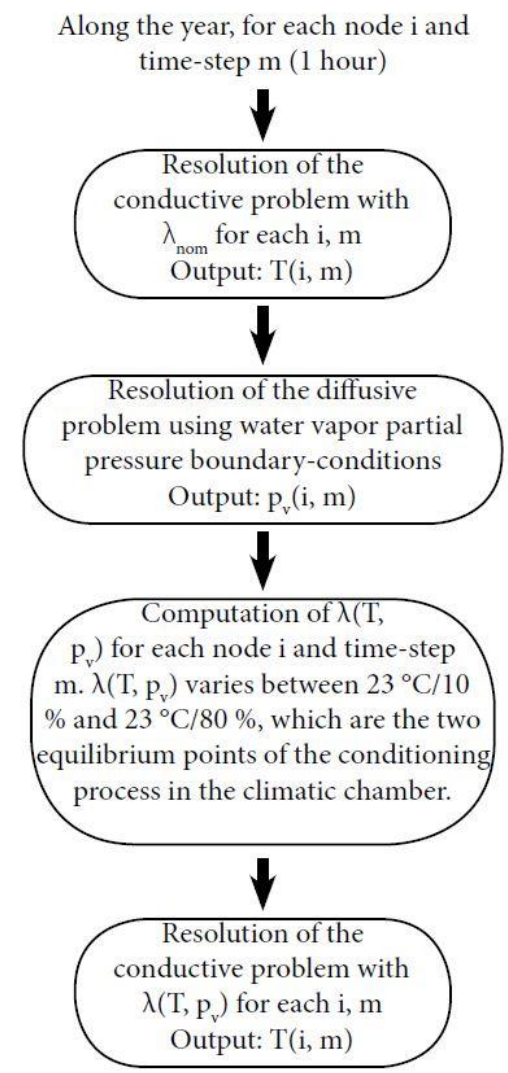

Figure 2: Flow diagram of the resolution of the MATLAB® model.

To characterize the impact of adopting nominal or variable thermal conductivity, the following quantities were elaborated:

1. Linear percentage trend deviation between the hourly values of specific heat fluxes calculated at the internal surface node with variable and those with nominal thermal conductivity $\lambda_{\text {nom }}$.

2. Annual specific energy difference (expressed as watthour per square meter): the cumulated deviations of the positive thermal losses (i.e., heat flux from the internal to the external side) and the negative thermal losses (i.e., heat flux from the external to the internal side), depending on the heat flux direction.

Table 1: Material properties.

\begin{tabular}{|c|c|c|c|}
\hline$\lambda_{\text {nom }}$ & $\boldsymbol{\rho}$ & $\boldsymbol{c}$ & $\boldsymbol{\mu}$ \\
\hline $\mathrm{W} \mathrm{m}^{-1} \mathrm{~K}^{-1}$ & $\mathrm{~kg} \mathrm{~m}^{-3}$ & $\mathrm{~J} \mathrm{~kg}^{-1} \mathrm{~K}^{-1}$ & - \\
\hline 0.107 & 363 & 1380 & 32 \\
\hline
\end{tabular}

\section{Results and discussions}

\section{Experimental activity}

Figure 3 shows both values and trends of thermal conductivity as a function of the specimen's temperature in three different moisture conditions: "as-is", humidified and dehumidified for one of the tested specimens. Similar values were obtained for the other ones. Thermal conductivity increases with temperature and the maximum difference obtained in the "as-is" condition is about $11.3 \%$. After a humidification process lasted 43 days and a mass increase of $6 \%$, thermal conductivity increased as well. The maximum difference obtained between humidified and "as-is" at a reference temperature of $23{ }^{\circ} \mathrm{C}$ was $13.2 \%$. About dehumidification, after 9 days and a mass loss of $5 \%$, thermal conductivity reached values similar to those found in the "as-is" condition (differences $<3 \%$ ). This means that thermal conductivity has a strong non-linear behaviour and hysteresis phenomena can be observed associated to humidification and dehumidification cycles.

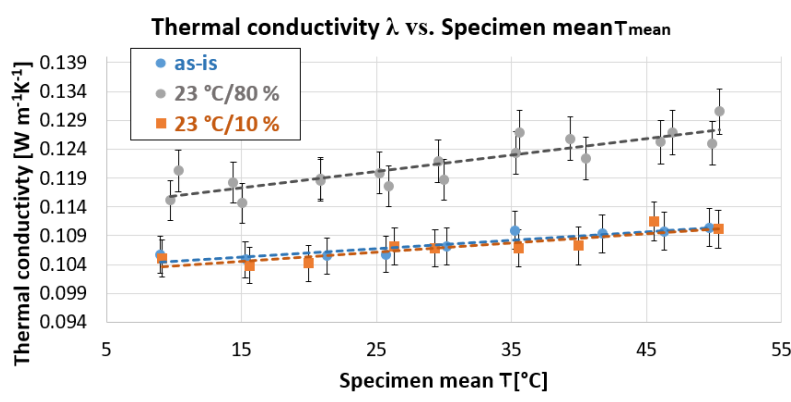

Figure 3: Thermal conductivity $\lambda$ vs. mean temperature of a specimen in three different moisture conditions: "as-is" (blue), humidified (grey) and dehumidified (orange). Vertical lines represent the measurement uncertainty.

Starting from the experimental data, a linear correlation between thermal conductivity, temperature and water vapour partial pressure was found, as shown in Equation 3 and in Figure 4.

$$
\lambda\left(T, p_{V}\right)=0.1+2.1 \cdot 10^{-4} \cdot T+7.4 \cdot 10^{-6} \cdot p_{V}
$$

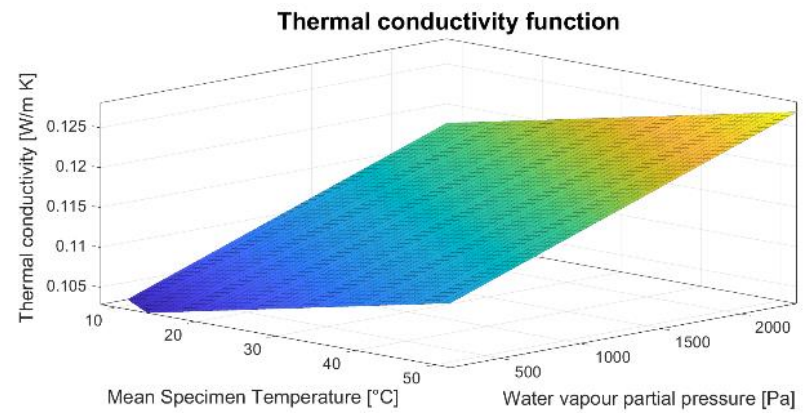

Figure 4: Plane describing the thermal conductivity vs. temperature and water vapour partial pressure.

Even if the EN ISO 10456 (CEN, 2007) suggests exponential functions for correction factors to thermal conductivity based on temperature and moisture content, 
in this work a simpler linear approximation was preferred for both. Indeed, in the analysed temperature range thermal conductivity tests showed a very linear trend against temperature, while, concerning the moisture content dependence, since only two conditioning states were considered in the experimental activity in controlled environment, the linear correlation was assumed as preferable. Planned future developments will include more experimental conditions and, thus, will allow for testing approximations with more complex functions.

Table 1, showed before, summarizes the general inputs of the model, i.e., the nominal values obtained from the experimental activity before conditioning tests. Nominal thermal conductivity was obtained in the "as-is" conditions at $23{ }^{\circ} \mathrm{C}$, while density was calculated after weighing specimens with an electronic scale. Specific heat capacity $c$ was taken from the literature. The vapor resistance factor resulted from calibration of the mass transfer model against experimental data. In details, the vapor resistance factor was adjusted, by comparison with the dehumidification test, by verifying that:

1. The simulated mass loss after 9 days of dehumidification is the same of the experimental one (i.e., $34 \mathrm{~g}$ );

2. simulated and calculated mean flux are corresponding. A $\mu$-value of 32 was first obtained in the calibration stage against the experimental dehumidification data and then checked as validation against the experimental humidification ones (i.e., a mass increase of $46.5 \mathrm{~g}$ in 43 days). The obtained value is consistent with the literature and the EN ISO 10456 (CEN, 2007), where suggested values range from 20 to 50 according to the moisture content.

\section{Overview of climates}

The annual averages of the air temperature and relative humidity are reported in Figures 5 and 6 . As it can be seen, colder localities are distributed in the northern and mountain regions of the country while warmer climates can be found in the southern regions. Higher relative humidity can be registered more often in the Po Valley and in different coastal climates. Focusing on the Po Valley, an exception can be found in Emilia-Romagna, which is characterized by average humidity remarkably lower than the neighbour climates and not representative of the long-term trend for this territory. This anomaly could depend either on a poor representativeness of the typical reference years or on the position of the weather stations used to collect the raw weather data. Indeed, the weather stations used in Emilia-Romagna to determine the typical reference years are installed in urban zones and, thus, can be affected by the urban heat island phenomenon. Typically, relative humidity in urban areas tends to be lower than in the rural ones because of the higher temperature.

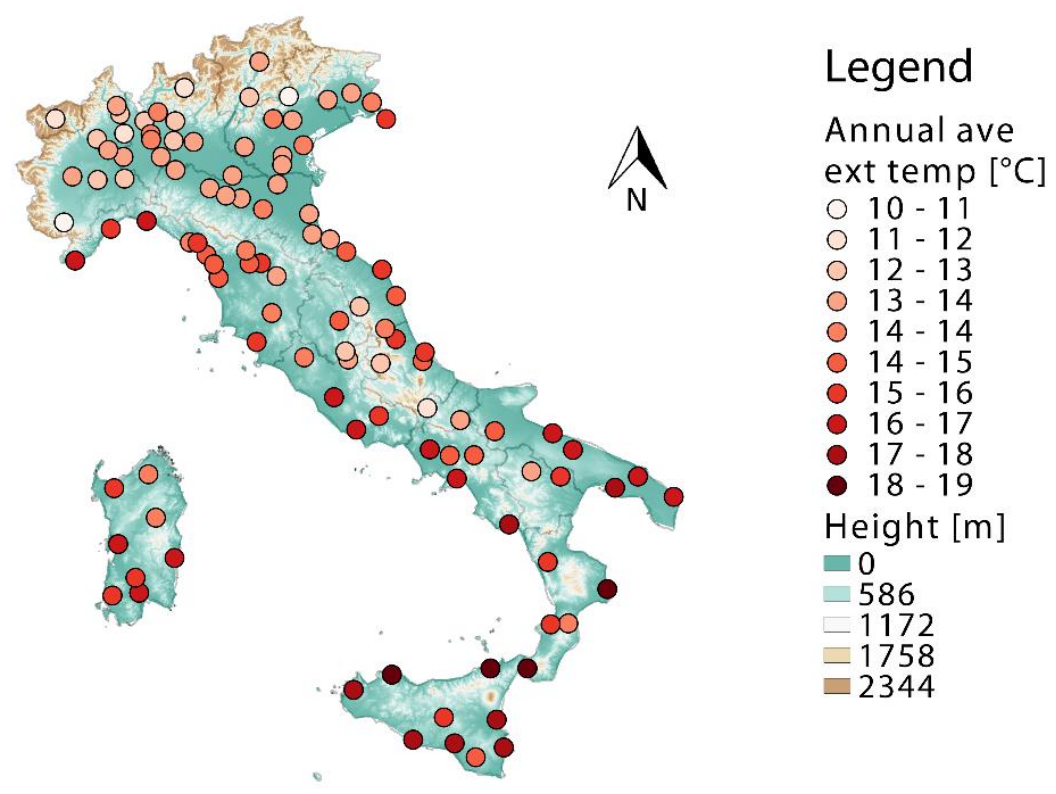

Figure 5: Annual average external temperature $\left[{ }^{\circ} \mathrm{C}\right]$ for each location. 


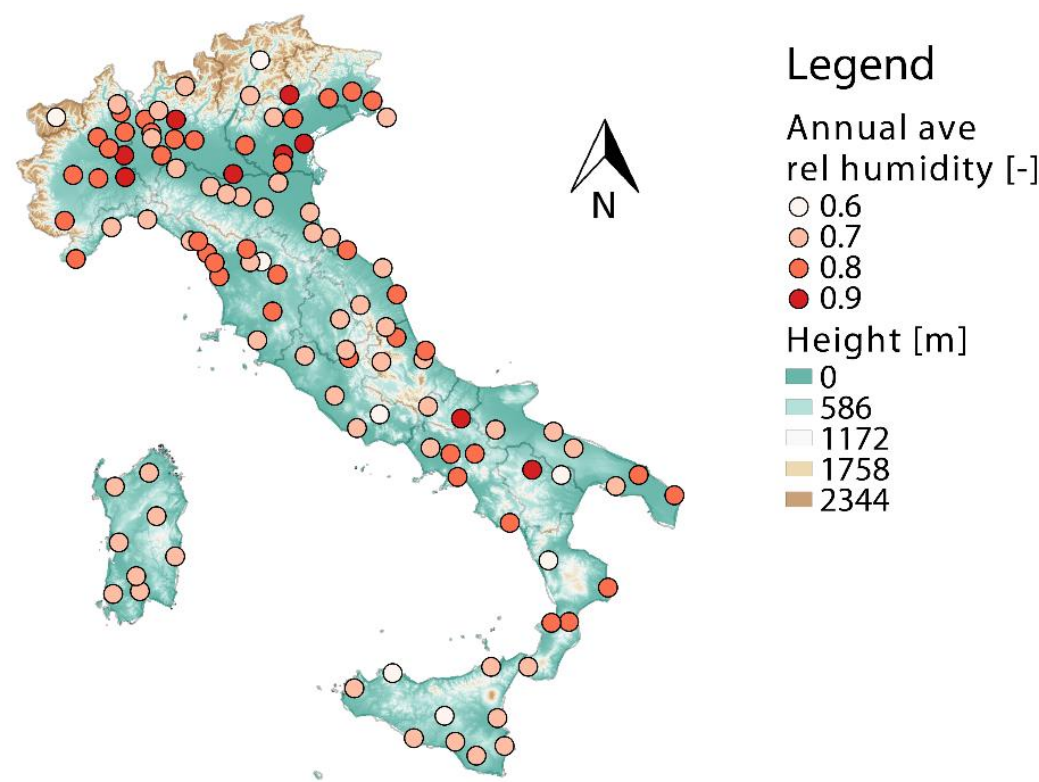

Figure 6: Annual average external relative humidity for each location [-].

\section{Analysis of trends in simulation results}

Comparing the heat fluxes calculated with variable thermal conductivity $\lambda\left(T, p_{v}\right)$ to those with the nominal one $\lambda_{\text {nom }}$, it can be observed that the former ones are generally larger than the latter. Figure 7 represents the percentage increase registered with variable thermal conductivity with respect the nominal one for each Italian climate. As it can be noticed, the phenomenon has a small incidence, namely between $1 \%$ and $3 \%$, but differences are not particularly marked across the country. On average the trend deviation is about $1.8 \%$. The first quartile of the trend deviations is $1.3 \%$, while the third quartile is $2.1 \%$.

Comparing Figure 7 to Figure 5, we can observe that locations with a low average external temperature have smaller trend deviations while higher percentages are detected mainly in the southern part of Italy and near the sea. Indeed, the maximum deviation $(3.1 \%)$ is observed in Catania, Sicily, while the minimum $(0.6 \%)$ is obtained in Livorno, Tuscany. Nevertheless, temperature differences are larger in the coldest regions and, consequently, so are the heat fluxes: while in the coldest cities the deviations are characterized by lower relative differences compared to the warmer cities, the absolute differences are larger.

Comparing Figure 7 to Figure 6, geographical correlations between trend deviation and the average relative humidity are less clear. As found in the experimental activity, higher moisture contents increase the timber thermal conductivity. Thus, the specific heat flux calculated with variable thermal conductivity is larger than that with nominal one. However, the annual average is not sufficient to describe the variability of the results. Indeed, calculated specific heat fluxes are influenced also by the variability of the ambient humidity: given the same annual average water vapour partial pressure, locations with more stable weather conditions can be characterized by higher percentage deviations than others.

If only the dependence of thermal conductivity on material temperature $\lambda(T)$ is considered, different results are registered. In this case, heat fluxes calculated with nominal thermal conductivity are slightly larger than those with variable conductivity. This occurs since nominal conductivity is determined at $23{ }^{\circ} \mathrm{C}$ while in simulations a constant internal condition of $20{ }^{\circ} \mathrm{C}$ is assumed, meaning that the internal surface node, where heat flux is estimated, is generally at temperature lower than the nominal one and so is the thermal conductivity. If thermal conductivity is expressed only as a function of water vapour partial pressure $\lambda\left(p_{v}\right)$, trends are similar to those discussed in case of $\lambda\left(T, p_{v}\right)$. However, percentage deviations are slightly larger, i.e., up to $4 \%$.

Considering the findings of all analyses with variable thermal conductivity, it can be seen that temperature and water vapor partial pressure have opposite effects on the simulated heat fluxes for the considered timber wall. Nevertheless, humidity affects more than temperature the thermal behaviour.

\section{Analysis of absolute deviations in simulation results}

After evaluating the trend deviations, absolute differences were analysed. Figures 8 and 9 show the differences of annual specific thermal energy transferred through the wall, comparing $\lambda\left(T, p_{v}\right)$ simulations to $\lambda_{\text {nom }}$ ones. Specifically, Figure 8 represents the annual specific positive thermal losses while Figure 9 shows the annual specific negative thermal losses. In both cases, by using a variable thermal conductivity $\lambda\left(T, p_{v}\right)$ an increase in the annual specific transmitted energy is noticed for each location. Considering the specific energy flowing towards the external (i.e., positive thermal losses), the average increase of losses is $290 \mathrm{Wh} \mathrm{m}^{-2}$ and the median value is $277 \mathrm{Wh} \mathrm{m}^{-2}$. First and third quartiles are, respectively, 
$239 \mathrm{Wh} \mathrm{m}^{-2}$ and $340 \mathrm{Wh} \mathrm{m}^{-2}$. The largest deviations are detected in the north and in mountain locations and the maximum increase happens in Rovigo, Veneto, with $451 \mathrm{Wh} \mathrm{m}^{-2}$. Lower deviations are detected in the southern regions, in agreement with the annual average temperatures of Figure 5. Confirming what said before, the use of a variable thermal conductivity affects more the colder locations in terms of absolute deviations. However, some exceptions are present: for instance, the lowest increase is not in the south but in Livorno, Tuscany, and the cities in Emilia-Romagna behave differently from the rest of the Po Valley.
About the specific negative thermal losses, the average is $113 \mathrm{Wh} \mathrm{m}^{-2}$ and the median value is $105 \mathrm{Wh} \mathrm{m}^{-2}$; the first quartile is $72 \mathrm{Wh} \mathrm{m}^{-2}$ and the third quartile $141 \mathrm{Wh} \mathrm{m}^{-2}$. The highest specific energy difference is found mainly in the warmer regions of the south of Italy. Indeed, the maximum increase of negative thermal losses was observed in Taranto, Puglia, with $244 \mathrm{Wh} \mathrm{m}^{-2}$. In the colder northern locations, the difference tends to be low and the minimum value is found in Emilia-Romagna $\left(29 \mathrm{Wh} \mathrm{m}^{-2}\right)$. Deviations are lower than for specific positive thermal losses because the negative ones, occurring mostly in the summer, are driven by smaller temperature differences.

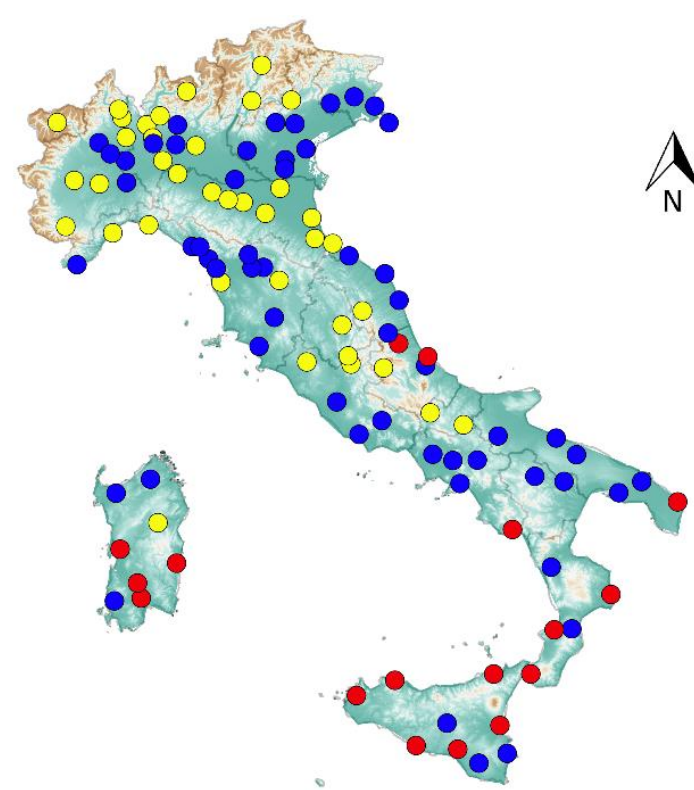

\section{Legend}

Mean dev of

actual specific

heat flux [\%]

\begin{tabular}{l}
1 \\
0 \\
\hline
\end{tabular}

Height $[\mathrm{m}]$

0

586

11172

$\square 1758$

2344

Figure 7: Trend deviation [\%] of the heat fluxes calculated with variable thermal conductivity with respect to the nominal one.

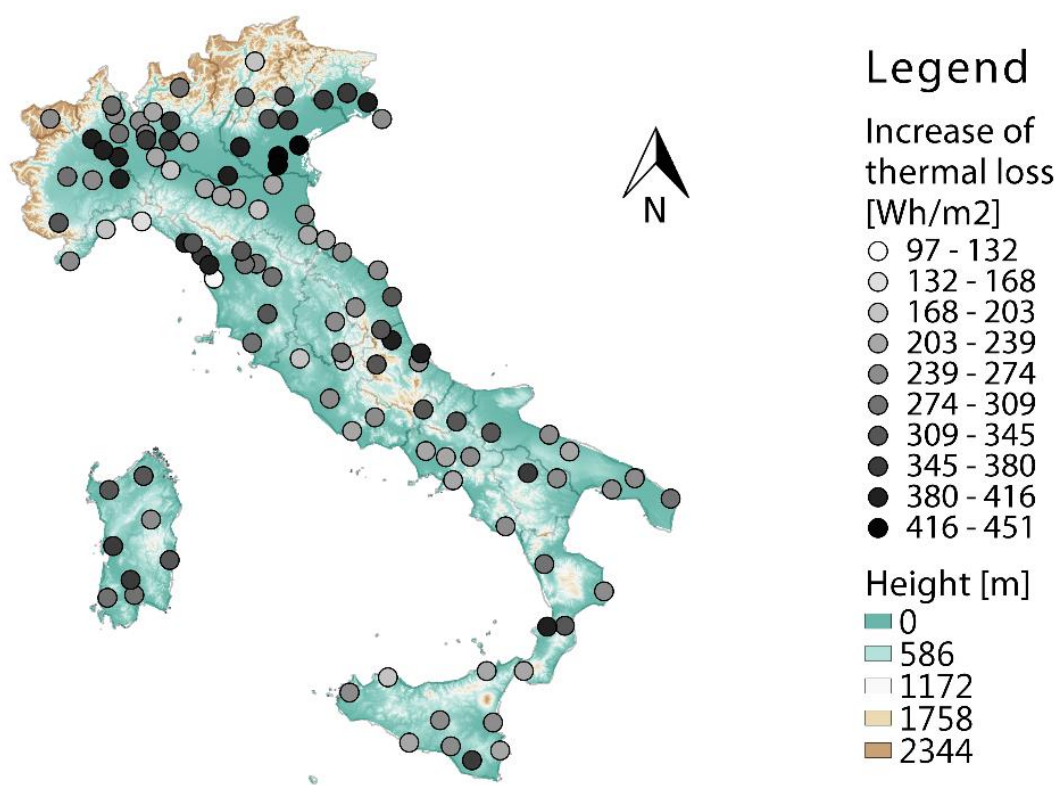

Figure 8: Increase of annual specific positive thermal losses calculated with variable thermal transmittance with respect to the nominal one $\left[\mathrm{Wh} / \mathrm{m}^{2}\right]$. 


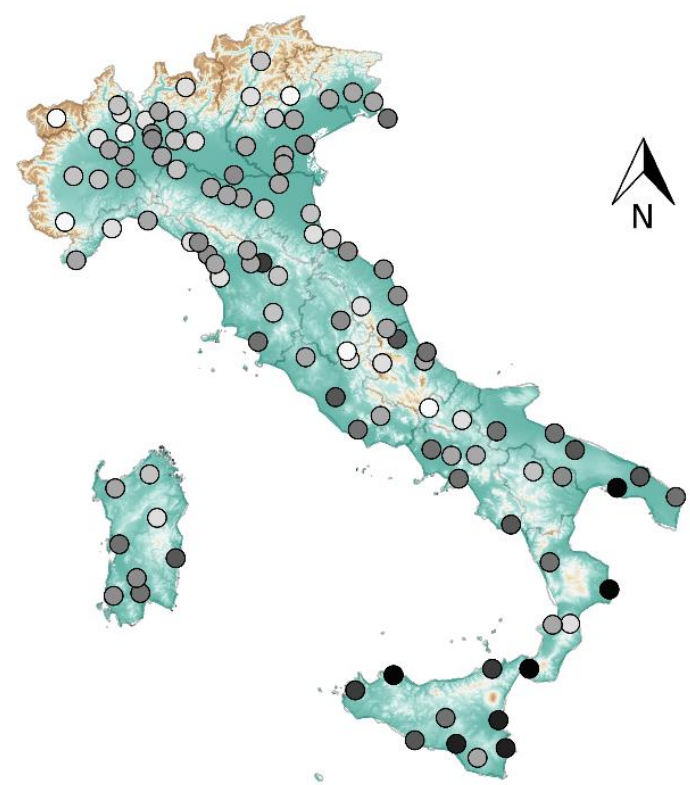

Legend

Increase of

thermal gain

[Wh/m2]

○ $29-50$

○ $50-72$

○ 72 - 94

○ $94-115$

- $115-136$

- $136-158$

- $158-180$

- 180-201

- $201-222$

- $222-244$

Height [m]

$\square 0$

$\square 586$

$\square 1172$

$\square 1758$

$\square 2344$

Figure 9: Increase of annual specific negative thermal losses calculated with variable thermal transmittance with respect to the nominal one $\left[\mathrm{Wh} / \mathrm{m}^{2}\right]$.

\section{Conclusion}

The aim of this work was to evaluate the uncertainty introduced in building energy simulation codes by adopting nominal material thermal properties without considering the dependence on material temperature and moisture content. In particular, the research focused on thermal conductivity and on timber, which is generally more sensitive to moisture content than other building materials. Specifically, spruce and $X L A M$ walls were studied.

In order to achieve the goals, first, an experimental campaign was carried out in laboratory, collecting all the information necessary to develop a correlation between thermal conductivity, material temperature and moisture content. In this stage, spruce specimens were tested considering average temperatures ranging from 10 to $50{ }^{\circ} \mathrm{C}$ and moisture contents resulting from an equilibrium condition with the laboratory environment, a humidification conditioning in a climate chamber kept at $23{ }^{\circ} \mathrm{C}$ and $80 \% R H$ and a dehumidification conditioning at $23{ }^{\circ} \mathrm{C}$ and $10 \% \mathrm{RH}$. The experimental results were employed to determine the variable thermal conductivity as a function of material temperature and water vapour partial pressure. A 1D finite difference $H M T$ model was then developed in MATLAB ${ }^{\circledR}$ environment and its unknown parameters calibrated against experimental dehumidification data and validated against the humidification ones. With such a model, the thermal behaviour of a $30 \mathrm{~cm} X L A M$ wall was simulated considering the typical reference years of 110 Italian locations.

Comparing the hourly specific heat fluxes and the annual specific transmitted energy, distinguishing positive and negative losses, obtained with variable and nominal thermal conductivities, we observed that:

- The adoption of nominal thermal conductivity instead of the variable one brings to a slight underestimation of the hourly heat fluxes for the tested spruce XLAM wall.

- The use of nominal thermal conductivity, however, has limited impacts on the simulated heat fluxes, which is generally between 1 and $3 \%$ of trend deviations.

- Considering separately the impact of temperature and humidity on thermal conductivity, it can be seen that, for the tested wall, the former one brings to larger heat fluxes if calculated with nominal values while the latter one leads to an underestimation. Nevertheless, moisture content has a larger incidence than temperature.

- The Italian climates show different trends, with the northern colder climates generally presenting smaller values of percentage trend deviations with respect to the southern warmer ones. However, analysing the differences in annual transmitted energy, the largest absolute differences are found in the coldest regions while the lowest in the warmest ones.

Future developments of the current research will be addressed to overcome the limitations of the developed numerical model. Indeed, the phase changes, the nonlinear behaviours due to timber humidification and dehumidification cycles, and the effects of some boundary conditions, such as the incident solar irradiance and precipitations, were not accounted. Moreover, with a more advanced model, new types of timber materials and walls will be tested. 


\section{Acknowledgement}

This research was funded by the project "Klimahouse and Energy Production", in the framework of the programmatic-financial agreement with the Autonomous Province of Bozen-Bolzano of Research Capacity Building.

\section{Nomenclature}

$c \quad=$ Specific heat $\left(\mathrm{J} \mathrm{kg}^{-1} \mathrm{~K}^{-1}\right)$

$C_{m} \quad=$ Storage moisture capacity $\left(\mathrm{kg} \mathrm{kg}^{-1} \mathrm{~Pa}^{-1}\right)$

$\delta_{p} \quad=$ Water vapor permeability $\left(\mathrm{kg} \mathrm{m}^{-1} \mathrm{~s}^{-1} \mathrm{~Pa}^{-1}\right)$

$H F M=$ Heat flow meter

$H M T=$ Heat and mass transfer model

$i \quad=$ Spatial node

$\lambda=$ Thermal conductivity $\left(\mathrm{W} \mathrm{m}^{-1} \mathrm{~K}^{-1}\right)$

$m \quad=$ Timestep

$\mu \quad=$ Water vapour resistance factor (-)

nom = Nominal

$p_{v} \quad=$ Water vapour partial pressure $(\mathrm{Pa})$

$\rho \quad=$ Density $\left(\mathrm{kg} \mathrm{m}^{-3}\right)$

RH = Relative humidity (\%)

$T=$ Temperature $\left({ }^{\circ} \mathrm{C}\right)$

$t \quad=$ Time $(\mathrm{s})$

$U=$ Thermal transmittance $\left(\mathrm{W} \mathrm{m}^{-2} \mathrm{~K}^{-1}\right)$

$X L A M=$ Cross-laminated

\section{References}

Abdou, A.A., and Budaiwi, I.M. (2004). Comparison of Thermal Conductivity Measurements of Building Insulation Materials under Various Operating Temperatures. Building physics 29(2), 171-184.

Baggio, P., Campanale, M., Deponte, F., and Moro, L. (2001). Analytical and Experimental Investigations on the heat transfer property on Moist Wood Wool Slabs. Thermal envelope \& building science 24, 211-225.

Bomberg M. T. and Shirtliffe C. J. (1978). Influence of Moisture and Moisture Gradients on Heat Transfer through Porous Building Materials. Proceedings from Thermal Transmission Measurements of Insulation. Philadelphia (USA). 19 September 1977.

Budaiwi, I. and Abdou, A. (2013). The impact of thermal conductivity change of moist fibrous insulation on energy performance of buildings under hot-humid conditions. Energy and Buildings 41(12), 1360-1367.

Chaker, A. and Sotehi, N. (2014). Numerical analysis of simultaneous heat and mass transfer in cork lightweight concretes used in building envelopes. Physics Procedia 55, 429-436.
European committee for Standardization CEN. (2001). UNI EN 12664. Determination of thermal resistance by means of guarded hot plate and heat flow meter methods. Dry and low moist products of medium and low thermal resistance.

European committee for Standardization CEN. (2007). EN ISO 10456. Building materials and products, Hygrothermal properties, Tabulated design values and procedures for determining declared and design thermal values.

Ferroukhi, M.Y., Belarbi, R., Limam, K., and Bosschaerts W. (2017). Experimental validation of a HAM-BES co-simulation approach. Energy procedia 139, 517523.

Fitzpatrick, J.J., O'Sullivan, C., Boylan, H., Cribben, O., Costello, D., and Cronin, K. (2013). Moisture sorption isotherm study of Sitka spruce, larch, willow and miscanthus chips and stems. Biosystem Engineering 115, 474-481.

Jerman, M. and Černý, R. (2012). Effect of moisture content on heat and moisture transport and storage properties of thermal insulation materials. Energy and Buildings 53, 39-46.

Karamanos, A., Hadiarakou, S., and Papadopoulos, A.M. (2008). The impact of temperature and moisture on the thermal performance of stone wool. Energy and Buildings 40(8), 1402-1411.

Luikov, A.V. (1975). Systems of differential equations of heat and mass transfer in capillary-porous bodies (review). International Journal of Heat and Mass Transfer 18, 1-14.

Rudtsch, S. (2000). Thermal conductivity measurements for the separation of heat and mass diffusion in moist porous materials. High temperature-high pressure 32, 487-92.

Straube, J, and Burnett, E. (1999). Review of Modelling Methods for Building Enclosure Design. Retrieved from:

http://www.civil.uwaterloo.ca/beg/Downloads/HAM _Modeling_Review.PDF

Suleiman, B.M., Larfeldt, J., Leckner, B., and Gustavsson, M. (1999). Thermal conductivity and diffusivity of wood. Wood Science and Technology 33(6), 465-473.

Troppová, E., Svehlík, M., Tippner, J., and Wimmer, R. (2015). Influence of Temperature and Moisture Content on the Thermal Conductivity of Wood-Based Fibreboards. Materials and Structures 40(12), 407783. 